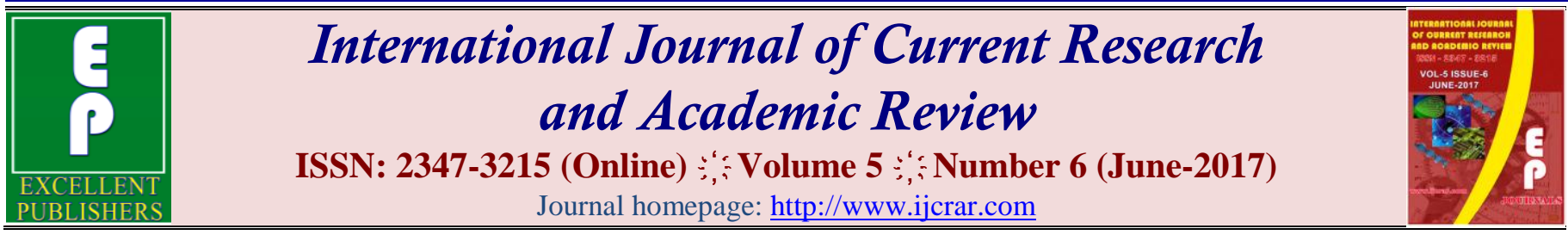

doi: https://doi.org/10.20546/ijcrar.2017.506.013

\title{
A Study on the Dimensions of Employee Attrition in the Business Process Outsourcing Industry in Chennai City, India
}

\author{
E. Baby*
}

Department of Commerce, Kanchi Shri Krishna College of Arts and Science, Kilambi, Kanchipuram, 631551, India

*Corresponding author:

\section{Abstract}

Human capital is the most crucial resource on which the Information Technology (IT) and Information Technology Enabled Services (ITES) depends. Apart from the location advantage that India has, the factor for the country's immense success in the overseas markets, is its abundant and cost effective human capital which is one of the key assets that has kept India sustain its edge in the ITES sector. Human Resource (HR) professionals all over the world, working in Call-Centre or Contact Centre or business process outsourcing (BPO) industry are leaving no stone unturned to formulate strategies to retain human capital, but in spite of all their trials the average attrition rate in the BPO this sector is still very high. This research paper mainly analysis the general reason for attrition in the work place. The study evaluates the attrition factors by measuring the intrinsic and extrinsic motivational factors. For the study the data collected through Questionnaire, the sample size is 90 various statistical tools used for the analysis purpose.
\end{abstract}

\section{Article Info}

Accepted: 05 June 2017

Available Online: 20 June 2017

\section{Keywords}

BPO, Attrition,

Intrinsic Motivation,

Extrinsic motivation.

\section{Introduction}

\section{Human resource challenge in business process outsourcing industry}

The greatest HR challenge facing globally distributed back-office and customer care centres is the retention of talented employees. Interviewees described attrition rates ranging from 15 to 40 percent in particularly active labour markets within countries such as India.

While some attrition in this industry is expected and may be beneficial, firms are concerned about not recouping their upfront investments in people. Clearly, employee retention is being influenced by a number of factors. The demand for experienced individuals, particularly At the supervisory level, is prompting firms to use signing bonuses and salary increases to entice talented individuals to switch firms. Also, these back-office and customer care centres - particularly those that are focused on working directly with customers - are often high-pressure, stressful environments.

Contact centres are often required to meet fairly stringent service level agreements regarding expected call volumes and average call length. These expectations cascade down to employees, and, as a result, many frontline workers face extremely demanding workloads. Given these conditions, many workers opt to leave the company soon after the firm has invested in their recruitment and training (Taylor and Bain, 2005). 


\section{Causes for attrition}

The reason for the high rate of attrition in the BPO sector particularly call centre segment range from lack of comfort of enrichment potential in terms of career growth. The growth of BPO industry is mainly depending on the cost effectiveness and quality of the manpower. Attrition is not a new problem and it has existed earlier and will continue to exist in any industry. In spite of the salaries and facilities being high, especially for a graduate who starts his / her career with a BPO company the average attrition rate is very high in this industry. There are numerous reasons for the attrition to be high which can be categorized into two broad classifications. The first can be called as "Drive Attrition" which is caused due to the employer; the second one can be termed as "Drag Attrition" which is caused due to the employee. The reasons for 'Drive Attrition' are due to employer's policy / policies of terminating the employee at the end of the contract period for employment. Also the quality policy of the BPO companies guides them to retain only the most productive employee and hence makes them to terminate employee at regular intervals. A BPO company operates 24 hours a day and 365 days a year. Untimely shifts which suit the foreign clients create lot of problems to the employees.

Symptoms of insomnia and even depression are caused due to change of 24-hour biological rhythm of the body, and also, loss of employee's personal life and hence, 'Drive Attrition' rate shoots up (Misra, 2007). The companies do not have a particular day as weekly off for its employees. The employees are not even entitled for national holidays declared by Government of India, as the company works with client calendar. The call agents can avail leave (which should not affect the schedule) only with prior consent, and any unauthorized absence is a sufficient reason for terminating an employee. 'Drag Attrition' is basically due to the host of insecurities and vulnerabilities associated with the taking up a career with a BPO company. They are:

\section{No career prospects}

The job of a call centre agent can be compared to a telemarketing or a telephone operator. Hence the scope to take up any other job or change of field is ruled out, as the experience gained in a call centre will not be of any importance. Many others quit, as the chance to climb up the corporate ladder is bleak. Only a very few get promoted to the cadre of team leader and as soon as promotions are announced, many frustrated employees quit.

\section{Lack of creativity}

The work in the BPO company needs no new creativity which can add to the enthusiasm of the employee. Voice calls are the only thing which governs the activity of the BPO. Further, BPO company work does not provide any scope for skill up gradation for the employee. The employer trains the employee to speak good English and nothing else which adds to the 'Drive Attrition' rate.

\section{Monotony of work}

The job remains same as to call clients and talk business. Same kind of lines repeated in the calls from the login point to logout point. Employees are bored of the same talks all through their working hours which lead to mental fatigue (Prakash and Chowdhury, 2010).

\section{Stressful job}

Also the nature of job in a typical BPO company is psychologically very stressful. The working hours are artificially created which affect the natural rhythm of human body. The symptoms of chronic fatigue, gastrointestinal problems, peptic ulcer, and insomnia can be attributed to the nature of working. The daily targets fixed to achieve push employees to work harder and harder leading to stress.

\section{Switching jobs for high salaries}

Poaching of employees by other competitive BPOs for higher salaries drives them to change jobs. The employees expect salary revision once in 4-6 months and if not they move to other organizations because of the rapid growth of the industry. Sometimes, personal reasons like marriage can also lead to attrition.

\section{Drive towards higher education}

Most of the employees with professional degrees like $\mathrm{BE}, \mathrm{MCA}$ and others appear for higher education or grooming them, for highly specialized courses quickly move out (BPO India, 2004).

\section{Human resource strategies to control attrition rate}

Companies have different kinds of strategies adopted to tackle the problem of retaining human capital. 
It ranges from cash incentives to career concern for the employee. As only 5 out of 150 employees become team leaders in a year, companies believe that cash incentives are a great way to get employees to stay on. They also offer management diplomas and MBA courses to their employees, as most fresh graduates want to study further.

Group medi-claim and personal accident insurance scheme: This scheme is to provide adequate insurance coverage for hospitalization expenses arising out of injuries sustained in an accident. This covers total / partial disablement / death due to accident and due to accidents.

Subsidized food and transportation: BPOs provide transportation facility to all the employees from home till office at subsidized rates or even at zero cost. Lunch is also provided free of cost.

Company leased accommodation: Some of the companies provide shared accommodation for all the outstation employees.

Recreation, cafeteria, ATM and gym facilities: The recreation facilities include pool tables, chess tables and coffee bars. BPO companies also have well equipped gyms, personal trainers and showers at facilities.

Personal health care: Some of the BPOs provide the facility for extensive health check-up. For employees with above 40 years of age, the medical check-up are given once in a year.

Loans: BPO companies provide loan facility on different occasions like medical emergency, wedding, also new recruits are provided with interest free loans to assist them in their initial settlement at the work location.

Giving employees a choice of rewards: Rewards are as different as the people who receive them and it doesn't make sense to give rewards that recipients do not find rewarding. Some people are excited about sports events, others about movies.

Performance incentives: Bonuses and incentives are paid after every quarter if the employee sustains in the organization and he gets extra rewards if his performance exceeds the target assigned to him.

Recruitment strategies: The recruitment manager keeps on innovating new techniques to hire the best people and the strategies are continuously renewed as per the changing scenario. Considering the high attrition rates the organization plans a very effective policy at the entry level (recruitment) which ultimately helps in sustaining human resource for the benefit of the organization (Joshi, 2004).

\section{IT and ITES sector in India}

India is the hottest destination for any company that wants to outsource its business processes. From a negligible size in early 2000 to a gigantic size today, the $\mathrm{BPO}$ sector has been growing at an unprecedented rate. In 2003, India accounted for 75 percent of the total BPO offshore delivery value that was expected to increase by 55 percent annually over the next five years (Neale, 2004). According to National Association of Software and Services Companies (NASSCOM), the Indian ITBPO industry (including domestic market) recorded an overall growth of 28 per cent (currency adjusted), clocking revenues of $\$ 108$ billion in 2012-13 up from $\$$ 39.6 billion in 2006-07. The year 2008 was a year of revolution for the Indian IT - BPO sector, as it began to re-engineer challenges posed by macroeconomic environment, with the worldwide spending aggregate has reached \$ 1.6 trillion, a growth of 5.6 per cent over the previous year. The domestic market has grown higher than that of the foreign market in 2012-13 compared to the previous year, while IT and ITES export has grown by around 10 per cent in 2012-13 (NASSCOM, 2013).

\section{Employment trends}

The IT/ITES sector has led to employment opportunities, both direct and indirect, of nearly 2.8 million and around 8.9 million respectively. This growth is expected to increase to more than 14 million (direct and indirect) by 2015 and to around 30 million by 2030 . The market size of the industry is expected to rise to $\$ 225$ billion by 2020 considering India's competitive position, growing demand for exports, Government policy support, and increasing global footprint. IT/ITES industry has led India's economic growth and this sector's contribution to the gross domestic product (GDP) has risen from 1.2 per cent in 1997-98 to an estimated 7.5 per cent in 2011-12.

As per the Economic Survey 2013-14, the IT/ITES industries has added 7.96 lakh jobs in one year, in the period ending September 2013. According to NASSCOM, employee base in the rural areas is expected to increase by over 10 times by 2013-14, compared to 5000 in 2009-10. India is the most preferred destination for engineering offshoring, which are encouraging 
foreign companies to offshore complete product responsibility to Indian ITES companies. Hyderabad is fast becoming the IT/ITES hub of India with new players hankering to get a foothold here, and existing players continuing to hire aggressively. Large companies such as Infosys, TCS, Genpact, Deloitte, Facebook, Bank of America, Thomson Reuters, Amazon, Google, Cognizant, Franklin Templeton among others, are growing their presence in the state.

According to Andhra Pradesh Government's estimates, the total IT/ITES sector hiring for 2012-13 could be at about 50000 professionals (Government of India, 2014).

\section{Problem of the study}

India has been one of the top most destinations as far as outsourcing of business activities is concerned. Many countries continue to outsource their business activities to India, through which the IT and ITES sector has been growing at a faster rate. It has attracted lakhs and lakhs of students to pursue education to get employment in this sector and thousands of them to in fact get employed year after year. The relatively higher level of salary being provided in this sector attracts thousands of young and fresh graduates to enter this sector, which is also the reason for the higher level of attrition. However, this higher level of attrition directly affects the BPO sector.

\section{Need for the study}

The need for the study lies in the detonation of the BPO industry in the recent years. Where on one hand the sector is growing with leaps and bounds, on the other the employee turnover has been alarmingly high, thus costing a lot to the company. The middle level and low level employees are victims of dearth of motivation and employee satisfaction also seems to be brandishing. The study is an attempt to assess the patterns of attrition in BPO and analyze the relationship among employee motivation.

\section{Objectives of the study}

The objectives of this thesis are:

1. To examine the demographic characteristics of the sample employees in the BPOs with the help of primary data;

2. To identify the factors influencing the level of attrition among the sample employees in the BPOs

\section{Hypothesis of the study}

The following hypothesis is framed in this study:

There is no significant difference in the factors influencing attrition among the Sample respondents.

\section{Methodology of the study}

The study involves an exhaustive study of the personal characteristics of the respondents; exploring the factors behind retention, and then comparing these factors across various personal characteristics. Besides gathering data through questionnaire, telephonic interviews have also been done with the respondents to improve the quality of the collected data.

\section{Tools of analysis}

The collected data have been examined with the help of statistical tools like descriptive statistics, t-test and correlation.

\section{Sample design}

The objective was to explore the dimensions of retention in BPOs based on primary data collected from field survey. Keeping in mind this objective of the study, a dedicated questionnaire was developed and was used as an instrument to gauge the dimensions of the questionnaire was sent to 100 respondents, of which 93 responded, thus making the response rate to be 93 per cent. Of these 90 completely filled questionnaires were verified and checked manually.

\section{Personal profile of respondents}

The first section of the instrument gathered information about the personal profile of the respondents which included age, gender, education, tenure and marital status. Gender, marital status and education were dichotomous variables. Age and tenure had three groups each. The characteristics are shown in table 1 .

Gender: The respondents are almost equally distributed in the category of gender. Of the 90 respondents 49 are males (54.4 per cent) and 41 are females (45.6 per cent). The BPO industry caters uniformly to both the genders, so the sample size is a homogeneous mix of both.

Age: Age level-wise, of the 90, 24 respondents (45.2 per cent) fall in the middle category i.e. between 26 and 30 . 
It is not surprising as the industry is characterized by the young lot as their primary workforce. Both the environment and the job description suit the young professionals which is a salient feature of the BPO industry. Also, 41 (26.8 per cent) and 25 (28 per cent) of the respondents come under the age categories of less than 25 and more than 30 respectively.

Marital status: Of the 90 respondents, 64 are unmarried i.e. 71 per cent and 26 are married ( 29 per cent). Although the instrument had other options like Separated, Divorced and Widow too, none of them fell in those categories. Thus, the categories have been reduced to two i.e. unmarried and married for the final analysis.

Education: The instrument had 3 categories namely under graduate, graduate and post graduate. Incidentally, all the respondents are either graduate or post graduate. Since there was no one in the category of under graduate, it has been done away with. Finally, the analysis considered only two categories in education. There are 44 respondents (48.8 per cent) in the category of graduates and 46 (51.2 per cent) in the category of post graduates.

Tenure: Of the 90 respondents, 40 per cent of the respondents i.e. 36 are less than 1 year old; 41.6 per cent of the respondents are 1-3 years old in their current organization and only 18.4 per cent respondents i.e. 17 respondents are more than 3 years old in their current organizations.

\section{Testing of hypotheses}

This section examines the hypotheses which have been framed in order to establish the factors of attrition and dimensions of retention among the respondents with the application of appropriate statistical tools.

Null hypothesis $\left(\mathbf{H}_{\mathbf{0}}\right)$ : There is no significant difference in the factors influencing attrition among the sample respondents.

Alternative hypothesis $\left(\mathbf{H}_{1}\right)$ : There is a significant difference in the factors influencing attrition among the sample respondents.

The difference in the factors influencing the attrition among the respondents is analysed here with the application of one sample t-test by taking the ranks given by them for each of the factor, which have been summated at the individual level. These values vary from 5 to 1 as noted earlier and table 3 presents the test result.

It is noted from the table that the calculated t-value of 78.174 is statistically significant at 1 per cent level and thus, the null hypothesis is rejected. This suggests that there is significant difference in the ranks assigned to the factors influencing the level of attrition among the respondents, since the male and female respondents, the graduate and post-graduate respondents and those who belong to different age groups perceive differently.

\section{Correlates and determinants of attrition}

After identifying the factors behind attrition, the next step is to find the correlates and the determinants of attrition. For this, first it is necessary to find out the means and standard deviations of the factors, which will help to understand them better. The respondents have been asked to rate the importance of each item responsible for their quitting on a scale of 5 , where 5 was very important and 1 was not at all important. After the factor analysis, when eight factors emerged, the score of each of the factors has been computed by taking out the mean of the items falling under each factor. For example, in order to calculate the mean of dispirited perceptual factors, the score of all the items i.e. low perceived value, lack of equality, lack of advancement opportunities, and incompatible policies have been added and then mean was calculated. Similarly, means and standard deviations have been calculated for all the factors.

These means and standard deviations are used to rank them. The ranking of the factors based on the means and standard deviations of each of the factors are shown in table 4.

It is noted that hostile organizational culture and substandard nature of job has the highest mean value of 3.09 , stating that most of the respondents consider substandard nature of job and the hostile organizational culture to be responsible for their quitting. Standard deviation for hostile organizational culture is 0.63 ; and for substandard nature of job, it is 0.98 . The means are closely followed by mystified career path (2.99), discontented personal factors (2.98), uncongenial organizational support (2.96), dispirited perceptual factors (2.85), low self-fulfilment factors (2.84), and finally unfavourable working conditions (2.72). Having calculated the mean and standard deviation of the independent variables i.e. factors of attrition, next is to 
calculate the same for the dependent variable i.e. probability of quitting the organization. The mean and standard deviation of the dependent variable is shown in table 5 .

Although the mean of probability of quitting the organization is around 3.25 , the standard deviation is relatively high at 1.15 , which indicates greater deviation in the opinions given by the respondents. The next step involved in computing the correlations between the independent variables and the dependent variable in order to find out the relationship between the two. The independent variables included eight dimensions of attrition and five personal characteristics. The correlation coefficient of the thirteen independent variables and one dependent variable is shown in table 6 .

Table.1 Characteristics of respondents

\begin{tabular}{|l|l|c|c|}
\hline \multicolumn{2}{|c|}{ Characteristics } & Number & Percentage \\
\hline \multirow{2}{*}{ Gender } & Male & 49 & 54.4 \\
\cline { 2 - 4 } & Female & 41 & 45.6 \\
\hline \multirow{3}{*}{ Age } & Less than 25 & 24 & 26.8 \\
\cline { 2 - 4 } & $26-30$ & 41 & 45.2 \\
\cline { 2 - 4 } & More than 30 & 25 & 28.0 \\
\hline \multirow{2}{*}{ Marital Status } & Unmarried & 64 & 71.0 \\
\cline { 2 - 4 } & Married & 26 & 29.0 \\
\hline \multirow{2}{*}{ Education } & Graduate & 44 & 48.8 \\
\cline { 2 - 4 } & Post-graduate & 46 & 51.2 \\
\hline \multirow{3}{*}{ Tenure } & Less than 1 year & 36 & 40.0 \\
\cline { 2 - 4 } & 1 to 3 years & 37 & 41.6 \\
\cline { 2 - 4 } & More than 3 years & 17 & 18.4 \\
\hline
\end{tabular}

Source: Primary data.

Table.2 Factors of items chosen for the study

\begin{tabular}{|c|c|c|}
\hline Factor & Item & Factor Name \\
\hline \multirow{4}{*}{1} & Low Perceived Value & \multirow{4}{*}{$\begin{array}{l}\text { Dispirited Perceptual } \\
\text { Factors }\end{array}$} \\
\hline & Lack of Equality & \\
\hline & Lack of Advancement Opportunities & \\
\hline & Incompatible Policies & \\
\hline 2 & Dissatisfied with Working Conditions & $\begin{array}{l}\text { Unfavourable Working } \\
\text { Conditions }\end{array}$ \\
\hline \multirow{3}{*}{3} & Power and Politics & \multirow{3}{*}{$\begin{array}{l}\text { Hostile Organizational } \\
\text { Culture }\end{array}$} \\
\hline & Dissatisfied with Colleagues & \\
\hline & Lack of Teamwork & \\
\hline \multirow{3}{*}{4} & Dissatisfied with compensation & \multirow{3}{*}{$\begin{array}{l}\text { Discontented Personal } \\
\text { Factors }\end{array}$} \\
\hline & Personal Reasons & \\
\hline & Dearth of self-motivation & \\
\hline \multirow{3}{*}{5} & Lack of Skill Variety & \multirow{3}{*}{ Substandard Nature of Job } \\
\hline & Monotonous Nature of Job & \\
\hline & Absence of Challenge & \\
\hline \multirow{3}{*}{6} & Irregular Working Hours & \multirow{3}{*}{$\begin{array}{l}\text { Uncongenial } \\
\text { Organizational } \\
\text { Support }\end{array}$} \\
\hline & Emphasis on quantity over quality & \\
\hline & Ineffective Supervision & \\
\hline \multirow{2}{*}{7} & Lack of Autonomy & \multirow{2}{*}{$\begin{array}{l}\text { Low Self-Fulfilment } \\
\text { Factors }\end{array}$} \\
\hline & Achievement not recognized & \\
\hline \multirow{2}{*}{8} & Poor Mentoring & \multirow{2}{*}{ Mystified Career Path } \\
\hline & Unsure of career growth & \\
\hline
\end{tabular}


Table.3 Testing the difference in the factors of attrition among the respondents

\begin{tabular}{|c|c|c|c|c|c|c|}
\hline \multirow{2}{*}{ Variable } & \multirow{2}{*}{ t-value } & \multirow{2}{*}{ Df } & \multirow{2}{*}{$\begin{array}{c}\text { Sig. (2- } \\
\text { tailed) }\end{array}$} & \multirow{2}{*}{$\begin{array}{c}\text { Mean } \\
\text { Difference }\end{array}$} & \multicolumn{2}{|c|}{$\begin{array}{c}\text { 95\% Confidence Interval of } \\
\text { the Difference }\end{array}$} \\
\cline { 5 - 7 } & & & & Lower & Upper \\
\hline Factor & $\mathbf{7 8 . 1 7 4} * *$ & 499 & 0.000 & 5.62400 & 5.4827 & 5.7653 \\
\hline
\end{tabular}

Note: ** Significant at 0.01 level.

Source: Computed from primary data.

Table.4 Means and standard deviation of the factors of attrition

\begin{tabular}{|c|l|c|c|}
\hline S. No. & \multicolumn{1}{|c|}{ Factor Name } & Mean & Std. Dev. \\
\hline 1 & Hostile Organizational Culture & 3.09 & 0.63 \\
\hline 2 & Substandard Nature of Job & 3.09 & 0.98 \\
\hline 3 & Mystified Career Path & 2.99 & 0.68 \\
\hline 4 & Discontented Personal Factors & 2.98 & 0.72 \\
\hline 5 & Uncongenial Organizational Support & 2.96 & 0.78 \\
\hline 6 & Dispirited Perceptual Factors & 2.85 & 0.82 \\
\hline 7 & Low Self-Fulfilment Factors & 2.84 & 0.75 \\
\hline 8 & Unfavourable Working Conditions & 2.72 & 1.06 \\
\hline
\end{tabular}

Source: Computed from primary data.

Table.5 Mean and standard deviation of probability of quitting

\begin{tabular}{|c|c|c|}
\hline Factor Name & Mean & Standard Deviation \\
\hline Probability of quitting & 3.25 & 1.15 \\
\hline
\end{tabular}

Source: Computed from primary data.

Table.6 Relationships of factors of attrition and personal characteristics with probability of quitting the organization

\begin{tabular}{|l|c|}
\hline Factors of Attrition & Probability of Quitting \\
\hline Substandard Nature of Job & $0.42^{* *}$ \\
\hline Dispirited Perceptual Factors & $0.30^{* *}$ \\
\hline Discontented Personal Factors & $0.23^{* *}$ \\
\hline Uncongenial Organizational Support & $0.23^{* *}$ \\
\hline Hostile Organizational Culture & $0.17^{* *}$ \\
\hline Low Self-Fulfilment Factors & $0.04^{\mathrm{NS}}$ \\
\hline Mystified Career Path & $0.03^{\mathrm{NS}}$ \\
\hline Unfavourable Working Conditions & $0.03^{\mathrm{NS}}$ \\
\hline Gender $(0=$ male, $1=$ female $)$ & $0.18^{* *}$ \\
\hline Marital Status $(0=$ unmarried, $1=$ married $)$ & $0.20^{* *}$ \\
\hline Education $(0=$ graduate, $1=$ post graduate $)$ & $0.29^{* *}$ \\
\hline Age & $0.06^{\mathrm{NS}}$ \\
\hline Tenure & $0.02^{\mathrm{NS}}$ \\
\hline
\end{tabular}

Note: ** Significant at 1 level.

The table clearly shows that out of thirteen independent variables, eight variables have significant correlations with the dependent variable that is probability of quitting the organization and all the correlations are positive. It should be noted that the dependent variable in the equation is the employee's probability of quitting the organization and all the independent variables are positively correlated with it. Out of eight dimensions of 
attrition, five are significantly correlated with probability of quitting and out of five personal characteristics, three are significantly correlated.

These five dimensions of attrition are substandard nature of job; dispirited perceptual factors; discontented personal factors etc., are positively correlated with the employees' probability of quitting an organization. The more the employee perceives the nature of job to be substandard, the more is his chance of quitting the organization. Similarly, the more dispirited he becomes with the perceptual factors like low perceived value, lack of equality, the more is he inclined towards leaving the organization. The only three variables which do not have a significant correlation are low self-fulfilment factors, mystified career path and unfavourable working conditions. Thus, it cannot be said with statistical significance that probability of quitting increases with the increase of uncertainty of career growth or poor mentoring or even achievement not being recognized. Thus, the correlations indicate that females show more probability of quitting as compared to males, similarly married employees have shown greater interest of quitting and finally in case of education, post graduates have expressed bigger probability of quitting.

\section{Conclusion}

This paper examined the dimensions of attrition among the respondents on the basis of both secondary and primary data. This suggests that the factors like higher salary expectation, lack of security, lack of social interaction, monotonous work, unusual working hours, pressure to perform on metrics, low perceived value, disillusioned employees, stress and burnout and lack of motivation have been identified through secondary data. Similarly, factors have also been identified through primary data and dimensions of attrition defined are dispirited perceptual factors, unfavourable working conditions, hostile organizational culture, discontented personal factors, substandard nature of job, uncongenial organizational support, low self-fulfilment factors, and mystified career path. Hostile organisation culture and sub-standard nature of job is responsibility for the quitting the job and a least factor for quitting the job is unfavourable working condition. The factors of items influencing the level of attrition among the respondents, since the male and female respondents, the graduate and post-graduate respondents and those who belong to different age groups perceive differently.

\section{References}

Morrow, P. 1993. The theory and measurement of work commitment, CT: JAL, Greenwich, pp. 19-34.

Mowday, R.T., Porter, L.W. and Steers, R.M. 1982. Employee organization linkages: The psychology of commitment, absenteeism and turnover, Academic Press, New York, pp. 9-18.

Mullins, L.T. 1999. Management and organizational behaviour, 5th edition, Financial Times Management, London, pp. 6-12.

Nakkiran, S., John Franklin, D. 2005. Business Process Outsourcing, Deep and Deep Publications Pvt. Ltd., New Delhi, pp. 29-37.

Parker, S. and Wall, T. 1998. Job and work design: Organizing work to promote well-being and effectiveness, Sage, Thousand Oaks, CA, pp. 3-17.

Patel, Alpesh, B. and Hemendra Aran. 2005. Outsourcing Success: The Business Imperative. Tata McGraw-Hill Publishing Company Limited, New Delhi, pp. 12-29.

Power, Mark, J. and Kevin, C. Desouza and Carlo Bonifazi. 2007. The Outsourcing Handbook, Kogan Page India, New Delhi, pp. 1-5.

Semmer, N. 2007. Individual differences, work stress and health, In M. J. Schabracq, J. A. M. Winnubst, and C. L. Cooper (Eds.), Handbook of work and health psychology, Wiley, 2nd edition, Chichester, UK, pp. 83-120.

Sengupta, Snigdha, Shelley Singh, Nelson Vinod Moses. 2013. BPO Industry report, Business World: ABP Pvt. Ltd., New Delhi, pp. 30-54.

Sparrow, Elizabeth Anne. 2007. A guide to Global Sourcing, Standford Street, South Asia Edition. British Computer society, London, pp. 76-86.

\section{How to cite this article:}

Baby, E., 2017. A Study on the Dimensions of Employee Attrition in the Business Process Outsourcing Industry in Chennai City, India. Int.J.Curr.Res.Aca.Rev. 5(6), 93-100. doi: https://doi.org/10.20546/ijcrar.2017.506.013 